\title{
Tumbas cadáveres: a materialidade da memória e a transição do mundo dos vivos ao mundo dos mortos
}

\author{
Tumbas cadaveres: la materialidad de la memoria y la transición del \\ mundo de los vivos a lo mundo de los muertos
}

\section{Transi Tombs: the materiality of memory and the transition from the world of the living to the world of the dead}

Amanda Basilio Santos ${ }^{1}$

\begin{abstract}
Resumo
Este trabalho é um recorte da pesquisa em desenvolvimento no mestrado em Memória Social e Patrimônio Cultural (PPGMP-UFPel) que, através da análise das representações mortuárias do século XV na Inglaterra, conhecidos como tumbas transi, ou tumbas cadáveres, pretende explorar uma nova percepção da experiência representativa da morte, assim como analisar a função memorial destas fontes tumulares e na construção visual da identidade de uma nobreza em crise e uma classe burguesa ascendente. Nesta apresentação iremos focar nos aspectos de fronteiras simbólicas entre a vida e a morte, assim como as dicotomias entre o que se foi e o que de fato se tornará que é construído materialmente através deste fenômeno memorial, sendo que esta apresentação visa ser apenas um referencial introdutório da pesquisa.
\end{abstract}

Palavras-Chave: Iconografia, Medievo, Memória, Tumbas transi.

\section{Resumen}

Este trabajo es parte de una investigación en desarrollo en el Masters en la Memoria Social y Patrimonio Cultural (PPGMP-UFPel) que, a través del análisis de las representaciones funerarias del siglo XV en Inglaterra, conocido como tumbas transi o tumbas cadáveres, que busca explorar una nueva percepción representante de la experiencia de la muerte, así como analizar la función de memoria de estas fuentes lápidas y construcción de la identidad visual de una nobleza en crisis y una clase burguesa en ascenso. En esta presentación nos centraremos en los aspectos de las fronteras simbólicas entre la vida y la muerte, así como las dicotomías entre lo que se fue y lo que realmente se convertirá, que se construye materialmente a través de este fenómeno conmemorativo, y esta presentación pretende ser sólo una introducción a nuestra investigación.

Palabras claves: Iconografía, Edad Media, Memoria, Tumbas transi.

\section{Abstract}

This work is part of a research in development in the master degree in Memória Social e Patrimônio Cultural (PPGMP-UFPel) that, through the analysis of mortuary representations of the 15th century in England, known as transi tombs or cadaver tombs, seek to explore a new perception of the representation of the experience of death,

\footnotetext{
${ }^{1}$ Mestranda em Memória Social e Patrimônio Cultural; Universidade Federal de Pelotas - UFPel, Pelotas, Rio Grande do Sul, Brasil. amanda_hatsh@yahoo.com.br
} 

e-ISSN 2016/Atual: 2525-7870 | e-ISSN 2015/2016: 2447-018X

as well as analyze the memorial function of these funerary sources and the visual construction of the identity of a nobility in crisis and a rising bourgeois class. In this presentation we will focus on aspects of symbolic boundaries between life and death, as well as the dichotomies between what has been and what actually will become that is built materially through this memorial phenomenon, and this presentation is intended to be only a introduction of this research.

Keywords: Iconography, Middle Ages, Memory, Transi Tombs.

\section{Introdução: objeto e conceitos}

Este trabalho é um recorte da pesquisa em desenvolvimento no mestrado em Memória Social e Patrimônio Cultural (PPGMP-UFPel) que, através da análise das representações mortuárias do século XV na Inglaterra, conhecidos como tumbas transi, ou tumbas cadáveres ${ }^{2}$, pretende explorar uma nova percepção da experiência representativa da morte, assim como analisar a função memorial destas fontes tumulares.

As tumbas que apresentaremos normalmente configuram-se dois níveis escultóricos: no nível superior temos uma representação de uma efígie funerária tradicional, com uma escultura que representa o falecido como que em estado de adormecimento, - em alguns casos com as mãos indicando uma reza - no auge de seu estado físico e com todos os elementos que carregam os valores de sua posição social em torno de seu corpo. Em um segundo nível, no andar inferior, temos a escultura de um corpo em decomposição ou na agonia da morte, tendo em torno de si elementos macabros como vermes e elementos pútridos que acompanham o processo natural da putrefação. Estas são as tumbas mais conhecidas, mas há várias formas de tumbas cadáveres, inclusive há algumas que trazem apenas o andar inferior, com a representação decomposta do falecido.

As tumbas pertencem sempre a pessoas que possuem grande influência social, sejam eles clérigos ou nobres, havendo alguns exemplos raros de homens que possuem origem burguesa e são economicamente bem-sucedidos, como a Tumba de John Barton e Isabella Barton.

Devemos considerar o quão dispendiosas tais tumbas eram, não apenas pelo local em que se encontram, pois elas são normalmente encontradas em catedrais e algumas em igrejas paroquiais, mas elas também exigem um maior número de esculturas se formos considerar as de duplo nível, custando, portando, o dobro do preço de tumbas convencionais. O fato de tais

\footnotetext{
2 Tumbas que possuem efígie recumbente que se encontra em leve ou avançado estado de decomposição. Embora nos preocupemos aqui com as tumbas inglesas, elas podem ser encontradas em bom número na França e na Itália, e em menor quantidade na Alemanha e nos países Baixos.
} 

e-ISSN 2016/Atual: 2525-7870 | e-ISSN 2015/2016: 2447-018X

tumbas serem alocadas no interior de edifícios religiosos denota o poder social e aquisitivo de tais indivíduos, pois eram espaços de exposição disputados.

$\mathrm{Na}$ Inglaterra há restante em torno de 150 exemplos, embora muitas tenham se perdido ou sido depredadas. O monumento mais antigo, preservado na Inglaterra, pode ser visto na Catedral de Lincoln, pertencente ao Bispo Richard Fleming, e o monumento mais moderno na Inglaterra, nesta linha artística seria a tumba do poeta John Donne, construída no século XVII.

As tumbas cadáveres são um fenômeno temporalmente muito específico: sua floração deu-se após a Grande Mortandade, mais comumente conhecida como Peste Negra. Porém não podemos reduzir a representação e a presença do mórbido como um evento oriundo apenas da experiência da peste de 1348 e de suas ocorrências posteriores (SHILLIAM, 1986).

Devemos considerar que o fenômeno de putrefação decorrente do processo da morte já era bem conhecido, mas por um processo de escolha não se desejava representá-lo em elementos funerários até o século XV e que mortes já ocorriam, embora sem a mesma escala. Portanto, ocorreram mudanças na percepção, uma mudança que não pode ser restrita a um episódio traumático como único gatilho, ocasionando uma diferente representação, sendo, portanto, o principal questionamento desta pesquisa os motivos pelos quais esta mudança tão drástica ocorreu.

Neste sentido, a pesquisa caminha na mesma direção apontada na tese de doutorado de Shilliam. Segundo ele, "the form of the tomb was moulded by contemporary cultural, temporal and spiritual innovations, as well as by the force of artistic personalities and the directives of patrons" (SHILLIAM, 1986, p. 3). Portanto, a partir das tumbas transi pretendemos abordar um fenômeno ímpar da escultura tumular e ao mesmo tempo tentar compreender o contexto que permitiu que este fenômeno acontecesse, levando-se em consideração eventos históricos específicos, assim como outras fontes da história inglesa, como o poema De Tribus Regibus Mortuis ${ }^{3}$, do século XV, que influenciou profundamente a iconografia deste período, que corresponde ao surgimento das tumbas transi.

Destacamos que as tumbas cadáveres possuem uma dupla instância memorial: ao mesmo tempo em que servem à memória do falecido representado em sua gisant ${ }^{4}$, ela também serve aos vivos como um apelo à memória da própria mortalidade. É assim a lembrança dos

\footnotetext{
${ }^{3}$ Poema inglês, também conhecido como The Tree Living and the Three Dead, tem sua autoria atribuída ao padre John Audelay, e está escrito no manuscrito MS. Douce 302, que pode ser consultado online. Sua influência foi além do solo inglês e representações visuais do poema são comuns também na França.

${ }^{4}$ Segundo a Encyclopaedia Britannica: "Gisant (French: 'reclining): in sepulchral sculpture, a recumbent effigy representing the person dying or in death. The typical gisant depicts the deceased in 'eternal repose', awaiting the resurrection in prayer or holding attributes of office and clothed in the formal attire of his social class or office." Disponível em: <http://global.britannica.com/art/gisant>, acessado em 20 de junho de 2016.
} 
que se foram e a lembrança da morte daqueles que ficam. Elas são memorização do passado (através do falecido) e memorização do tempo presente e projeção do futuro inevitável (através do apelo aos vivos, lembrando-os de sua transitoriedade).

Deste modo, salientamos o fato destas tumbas serem sempre atuais, pois por mais que elas sejam parte da manutenção da memória de pessoas que as encomendaram, elas estão sempre atuando sobre os vivos que as contemplam, pois elas pretendem comunicar e lembrar, sempre, a condição humana, e a mortalidade é um atributo atemporal.

Esta dupla instância memorial deve ser problematizada, e argumentamos que as tumbas cadáveres são veículos de comunicação e manutenção dos que se foram com aqueles que os contemplam. O apelo feito através da dramaticidade visual e da humildade e fragilidade exposta através da efígie cadavérica permite empatia do expectador, cumprindo parte da intenção deste elemento tumular que intenciona angariar rezas para a alma do falecido.

Assim sendo, há a manutenção da memória do falecido, a ativação da memória dos observadores de sua própria fragilidade e estado de igualdade ao morto, e, por fim, a comunicação através do apelo dramático, que deve gerar a reação de oração e contemplação. Assim sendo, as tumbas cadáveres são patrimônios ativos dentro do espaço que ocupam.

Para compreender esta dupla instância memorial, destacamos o conceito de sóciotransmissores. Segundo Candau os sóciotransmissores são "todas as produções e comportamentos humanos que estabelecem uma cadeia causal cognitiva social ou cultural entre pelo menos duas mentes-cérebro [...] Vários objetos desempenham um papel fundamental na sócio-transmissão" (CANDAU, 2009, p. 8), deste modo há de ter ao menos dois agentes e o estabelecimento de uma transmissão de informação, mais especificamente ele diz que:

\footnotetext{
Pocos objetos patrimoniales responden tan bien a su vocación de memoria como los lugares importantes, los monumentos y las estatuas. Los 'difusores' de la memoria por excelencia son los monumentos a los muertos, las necrópolis, los osarios, etc. y, de manera más general, todos los monumentos funerarios que son el suporte de una fuerte memoria afectiva (CANDAU, 2002, p. 92-93).
}

Como é destacado pelo próprio Candau, os monumentos funerários cumprem um importante papel sóciotransmissor, sendo que as tumbas transi, em sua mensagem específica de tentativa de comunicação e preocupação em estabelecer uma relação de parecença entre aquele representado e aquele que mira. É, portanto, a transmissão da memória e o engajamento de uma relação de associação entre os sujeitos. 


\section{Fronteiras simbólicas: a construção do que se foi, a construção do que se é.}

Como destacamos anteriormente, as tumbas transi cumprem um importante papel memorial na sociedade, e esta se concretiza materialmente através dos elementos escultóricos que exibem uma fronteira comum a todos os seres humanos: a passagem ao mundo que pertence aos mortos.

Esta passagem, que é na verdade uma mudança de condições de existências, está explícita nas escolhas feitas na concepção destas obras funerárias. Ao contrário do que tínhamos tradicionalmente, a passagem não é tranquila, serena, sagrada. A morte aqui nos é apresentada de modo agonizante, decadente e sofrida. Os mortos não estão mais resignados! Aqui eles exigem a atenção dos vivos, quebrando as barreiras que os separam, diminuindo as fronteiras e pedindo que estes orem por suas almas, pois logo estarão na mesma situação que eles.

Este novo paradigma visual tumular fica claro na tumba transi de Alice de la Pole ${ }^{5}$, onde na parte superior temos uma escultura tradicional, onde a duquesa é representada de modo sereno e cercada pelos seus aparatos simbólicos que definem sua posição política ocupada na sociedade em seu período de vida terrena (Figura 1).

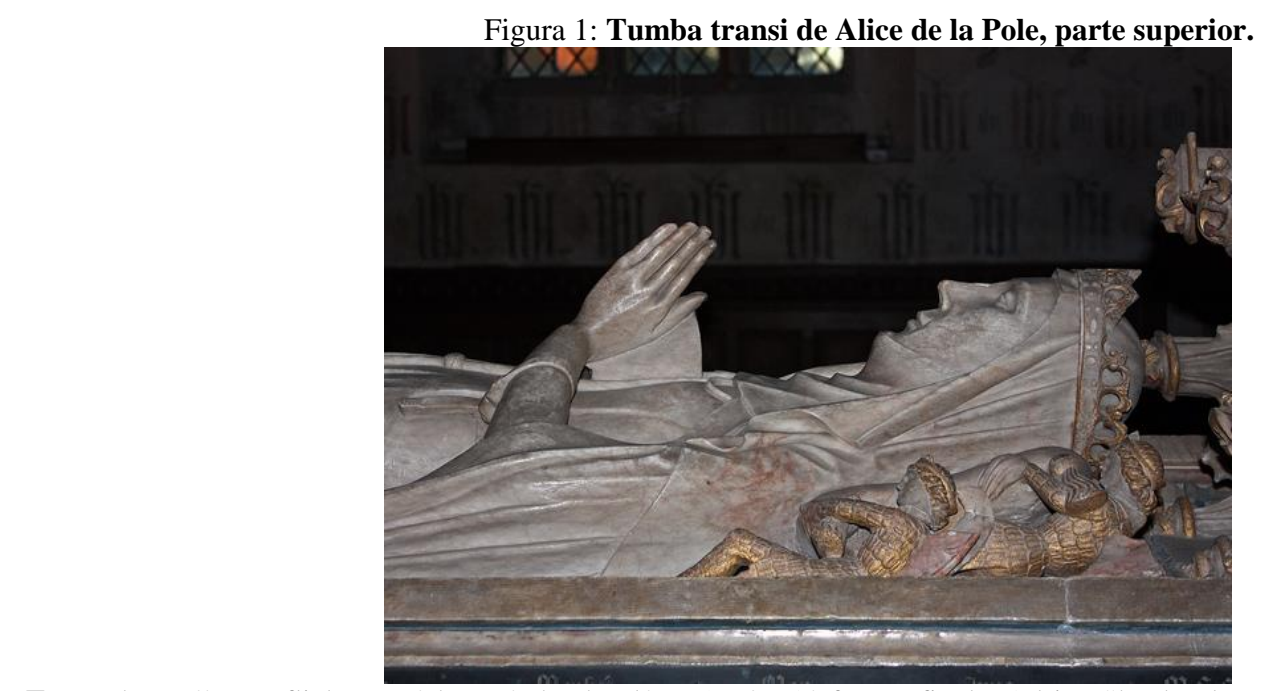

Fonte: https://www.flickr.com/photos/ashepherd/6695664971/, fotografia de Adrian Shepherd, acessado pela última vez em 26 de agosto de 2016.

Anjos apoiam a sua cabeça que descansa em um travesseiro, e encontra-se coroada por uma clássica coroa de duquesa. Suas mãos estão como em estado de oração, e seus olhos

\footnotetext{
${ }^{5}$ Duquesa de Suffolk, viveu entre 1404-1475. Era neta de Thomas Chaucer, escritor do The Canterbury Tales. Fora casada quatro vezes, dado ao falecimento de seus maridos. Em seu quarto casamento tornou-se Dama de Companhia de Margarida de Anjou e fora Patrona das Artes.
} 
abertos ao mundo do Além, do qual agora ela é integrante. Os olhos de sua gisant, portanto, vislumbram algo que não vemos, pois não ultrapassamos as fronteiras entre o mundo dos vivos para o mundo dos mortos.

Porém, ao olharmos o nível inferior de sua tumba, temos uma representação de seu estado atual, que em nada se assemelha com o nível superior. Aqui, seu cadáver com aparência agonizante, com a boca aberta, como a exalar seu último suspiro, com a carne carcomida, nos apresenta estágios de putrefação naturais ao corpo humano após a morte (Figura 2).

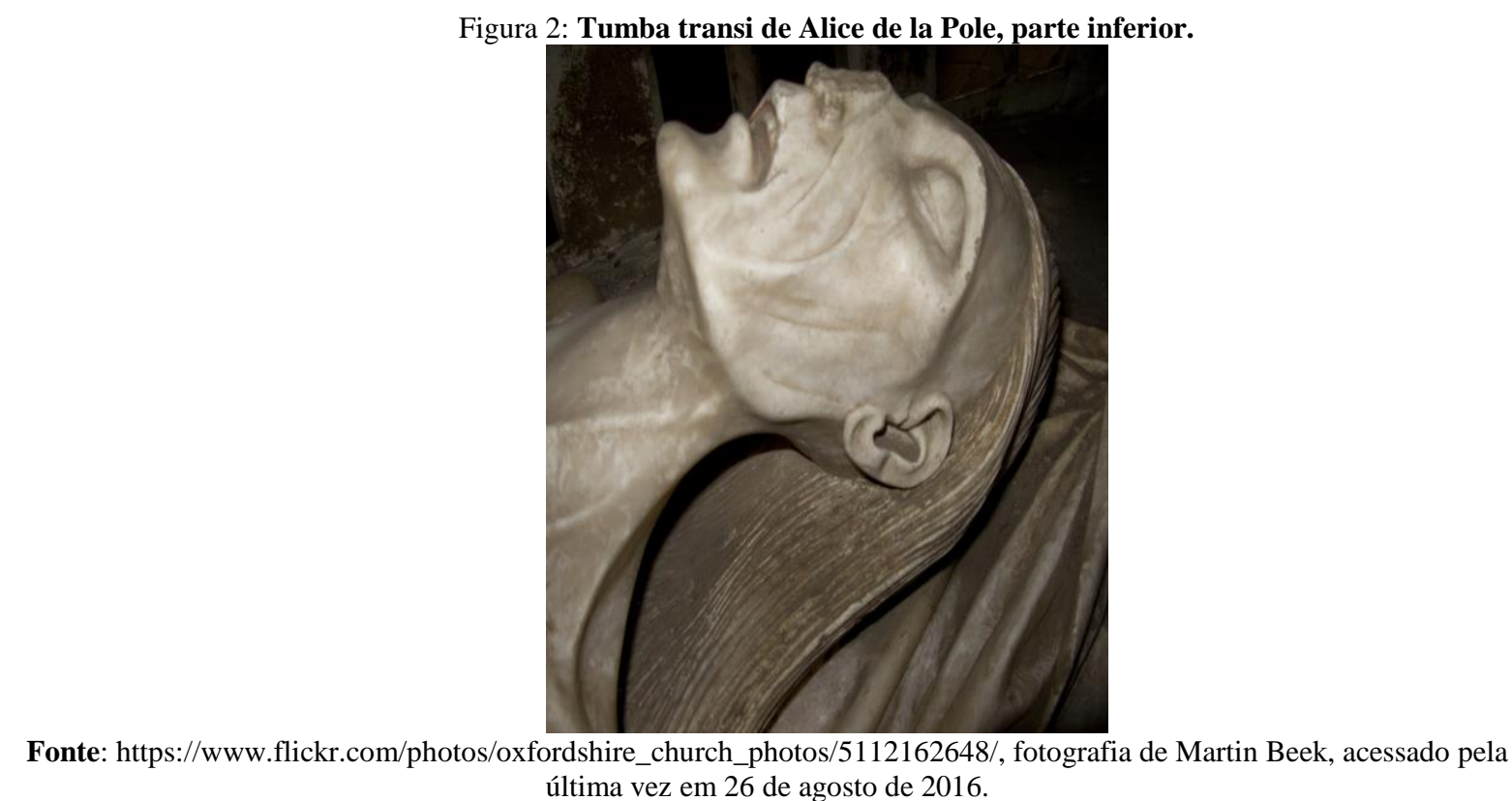

Fica claro nesta tumba as fronteiras simbólicas estabelecidas entre o que Alice fora e o que Alice agora o é. Mais do que isso, é feito uma aproximação com todos aqueles que observam seu monumento, pois é edificado uma humildade em seu novo estágio, que a iguala a qualquer pessoa, despindo-a de seu antigo prestígio terreno. Tal aproximação tornou-se vital em um período em que a nobreza se encontra em crise na Inglaterra, e vemos estas construções visuais serem adotadas também por altos membros do clero e pela ascendente classe burguesa.

Em união ao conceito de sóciotransmissão, destacamos o conceito de imagem memorial (Memorialbild) de Horch que define que para que se constitua em tal deve cumprir quatro funções: estabelecer uma comunidade entre os vivos e os mortos; indicar a presença do morto na sociedade; lembrar dos deveres recíprocos entre os vivos e os mortos; garantir que se dê a performance de tais deveres no futuro (HORCH, 2001, p.15). 
Como destaca Horch, as tumbas consolidam diversos laços de solidariedade entre os vivos e os mortos e embora a memória institucional se consagre através da lembrança de Cristo, da teologia, dos marcos religiosos, e seja praticada nas datas determinadas a relembrar tais acontecimentos e personagens, no mundo popular, a memória "cristalizou-se sobretudo nos santos e nos mortos" (LE GOFF, 1990, p. 446).

Os mortos são centrais na memória social medieval, e aqueles cuja memória é nutrida estão nos centros das igrejas através de seus monumentos tumulares e registrados nos libri memoriales $^{6}$. Esta lembrança feita através do registro nos libri, anda de mãos dada ao esquecimento imposto aqueles considerados indignos, pois a excomunhão é aliada desta damnatio memoriae.

Estas tumbas e sua constituição alegórica coloca-se em um ponto de transição, tal como eram os cemitérios medievais: marcavam a passagem de um estágio para outro, de uma existência terrena e profana para uma existência eterna e sagrada (SCHMITT, 1999). Porém, embora carreguem esta promessa, são uma lembrança das auguras enfrentadas em um espaço intermediário da geografia do Além, o Purgatório. Tais construções visuais, lembranças e corporificações de instâncias invisíveis, trazem consequências ao mundo tangível, e geram uma cadeia de relações que devem ser mantidas entre os vivos e os mortos, para manutenção do equilíbrio.

\section{Considerações finais}

Esta é uma pesquisa que ainda se encontra em fase inicial, portanto, o que se intenciona é apresentar as problemáticas levantadas e os caminhos que serão trilhados na pesquisa, através da apresentação de algumas Tumbas Cadáveres como método exemplificativo. Em aspectos gerais, no mundo visual, podemos ver um novo modo de se perceber diante da morte e uma nova percepção do próprio processo sofrido após o falecimento, um processo que já não é mais escondido, mas é exibido em forma de escultura dentro dos mais influentes prédios religiosos, locais sagrados e de imagens sagradas, mas também locais de convivência, que os torna zonas de grande visibilidade para as imagens que ali estão presentes.

Podemos ver que as tumbas cadáveres nos oferecem mais do que um testemunho artístico, elas são fontes importantes para a compreensão do homem diante da morte em um contexto específico. Também nos auxiliam a entender como as famílias nobres e os

\footnotetext{
${ }^{6}$ Livros das paróquias nos quais constam os nomes daqueles sujeitos considerados importantes e dignos, que tinham uma dupla função: manter a memória destes falecidos e dedicar-lhes orações, auxiliando a passagem pelo Purgatório e a chegada aos Céus.
} 
indivíduos se constituíam como elite e a relação delas perante a comunidade, pois estas tumbas capelas possuem função de status para os patronos e o papel de expiação para os espectadores, que através delas conseguiam oportunidade caritativa, orando pela alma do nobre, ao mesmo tempo que era um momento reflexivo sobre a mortalidade, e desse modo, sobre o viver (DRESSLER, 2008), finalizamos com uma colocação de Souza que diz que:

\begin{abstract}
A arte funerária, ao contrário do que se pode pensar, abrange uma memória coletiva, corresponde a um objeto de amplos sentidos e de representação social. A visualização de fenômenos socioculturais na arte tumular foi a base de desenvolvimento deste estudo e conclui-se, a partir dele, que a arte funerária é muito mais que um elemento decorativo; é, sim, um meio de documentação históricosocial, que identifica a coletividade a que pertence (SOUZA, 2007, p. 10).
\end{abstract}

Concluindo, as tumbas transi se apresentam como uma fonte rica em possibilidades de análise, se apresentando como um importante fenômeno artístico, uma ocorrência memorial e, por fim, um sintoma cultural.

\title{
4. Referências
}

CANDAU, J. La métamémoire ou la mise en récit du travail de mémoire. Centre AlbertoBenveniste, avril, 2009.

CANDAU, J. Antropologia de la Memória. Buenos Aires: Del Sol, 2002. DRESSLER, R. Gender as Spectacle and Construct: The Gyvernay Effigies at St. Mary's Church, Limington. Different Visions, Nova York, 1, 2008. 1-24.

KING, P. M. Contexts of the Cadaver Tomb in Fifteenth Century England. York: University of York, v. Tese de doutorado, 1987.

NORA, P. Entre história e memória: a problemática dos lugares. Revista Projeto História, São Paulo, v. 10, p. 7-28, 1993.

PANOFSKY, E. Tomb Sculpture. Nova York: H. W. Janson, 1964.

PANOFSKY, E. Significado nas Artes Visuais. São Paulo: Perspectiva, 1979.

PAREYSON, L. Os problemas da estética. São Paulo: Martins Fontes, 1997.

ROCHA, C. Arte: um desafio para Clio. O Olho da História, Salvador, v. 16, julho 2011.

SHILLIAM, N. J. Foreign Influences on and Innovation in English Tomb Sculpture in the First Half of the Sixteenth Century. Tese de Doutorado. Warwick: Warwick University, 1986.

SCHMITT, J.-C. (1999). Os vivos e os mortos na sociedade medieval. São Paulo: Companhia das Letras. 

e-ISSN 2016/Atual: 2525-7870 | e-ISSN 2015/2016: 2447-018X

SOUZA, D. C. Arte Tumular: uma expressão social por meio de signos da morte. Disponível em: <http://www.mackenzie.com.br/fileadmin/Graduacao/CCL/projeto_todasasletras/inicie/Denis eSouza.pdf >. Acessado em 20 de junho de 2016.

WELCH, C. Cadaver Monuments in England. The Courtauld Institute of Art, p. 1-16, Junho 2014. 